\title{
ON A KY FAN TYPE INEQUALITY DUE TO H. ALZER
}

\section{JAMAL ROOIN}

Abstract. Let $A_{n}$ and $H_{n}$ (respectively, $A_{n}^{\prime}$ and $H_{n}^{\prime}$ ) be the weighted arithmetic and harmonic means of $x_{1}, x_{2}, \ldots, x_{n}$ (respectively, $\left.1-x_{1}, 1-x_{2}, \ldots, 1-x_{n}\right)$, where $x_{i} \in(0,1 / 2](i=1,2, \ldots$, $n ; n \geqslant 2)$. We mainly show that, if not all of the $x_{i}$ 's are equal, then

$$
\min _{1 \leqslant i \leqslant n} \frac{x_{i}}{1-x_{i}}<\frac{A_{n}^{\prime}-H_{n}^{\prime}}{A_{n}-H_{n}}<\max _{1 \leqslant i \leqslant n} \frac{x_{i}}{1-x_{i}},
$$

which is a refinement and converse of the Ky Fan type inequality $A_{n}^{\prime}-H_{n}^{\prime} \leqslant A_{n}-H_{n}$ due to $\mathrm{H}$. Alzer. Some parallel and related results are also discussed.

Mathematics subject classification (2010): 26D15.

Keywords and phrases: A-G-H inequality, Ky Fan's inequality.

\section{REFERENCES}

[1] H. Alzer, An inequality for arithmetic and harmonic means, Aequations Math. 46 (1993), $257-263$.

[2] H. Alzer, On an additive analogue of Ky Fan's inequality, Indag. Mathem., N.S. 8 (1997), 1-6.

[3] H. AlzER, The inequality of Ky Fan and related results, Acta Appl. Math. 38 (1995), 305-354.

[4] H. AlZER, Ungleichungen für geometrische und arithmetische Mittelwerte, Proc. Kon. Nederl. Akad. Wetensch. 91 (1988), 365-374.

[5] E. F. Beckenbach And R. Bellman, Inequalities, Springer-Verlag, Berlin, 1961.

[6] P. S. Bullen, D. S. Mitrinović And P. M. VAsić, Means and their inequalities, Springer-Verlag, Reidel, Dordrecht, 1988.

[7] D. I. CARTWRIGHT AND M. J. FIELD, A refinement of the arithmetic mean-geometric mean inequality, Proc. Amer. Math. Soc. 71 (1978), 35-38.

[8] P. R. MERCER, A note on Alzer's refinement of an additive Ky Fan inequality, Mathematical Inequalities \& Applications 3 (2000), 147-148.

[9] J. RooIn, An approach to Ky Fan type inequalities from binomial expansion, Mathematical Inequalities \& Applications 11 (2008), 679-688.

[10] J. Rooin, On Ky Fan's inequality and its additive analogues, Mathematical Inequalities \& Applications 6 (2003), 595-604.

[11] J. SAndor, On an inequality of Ky Fan II, Inter. J. Math. Educ. Tech. 22 (1991), 326-328. 